\title{
Testing the shape-similarity hypothesis between particle-size distribution and water retention for Sicilian soils
}

\author{
Chiara Antinoro, Vincenzo Bagarello, Vito Ferro, Giuseppe Giordano, Massimo lovino \\ Dipartimento dei Sistemi Agro-Ambientali, Facoltà di Agraria, Università degli Studi di Palermo, \\ Italy
}

\begin{abstract}
Application of the Arya and Paris (AP) model to estimate the soil water retention curve requires a detailed description of the particlesize distribution (PSD) but limited experimental PSD data are generally determined by the conventional sieve-hydrometer ( $\mathrm{SH})$ method. Detailed PSDs can be obtained by fitting a continuous model to SH data or performing measurements by the laser diffraction (LD) method. The AP model was applied to 40 Sicilian soils for which the PSD was measured by both the SH and LD methods. The scale factor was set equal to 1.38 (procedure AP1) or estimated by a logistical model with parameters gathered from literature (procedure AP2). For both SH and LD data, procedure AP2 allowed a more accurate prediction of the water retention than procedure AP1, confirming that it is not convenient to use a unique value of for soils that are very different in texture. Despite the differences in PSDs obtained by the SH and LD methods, the water retention predicted by a given procedure (AP1 or AP2) using SH or LD data was characterized by the same level of accuracy. Discrepancies in the estimated water retention from the two PSD measurement methods were attributed to underestimation of the finest diameter frequency obtained by the LD method. Analysis also showed that the soil water retention estimated using the SH method was affected by an estimation bias that could be corrected by an opti-
\end{abstract}

Correspondence: Vincenzo Bagarello, Dipartimento dei Sistemi AgroAmbientali, Facoltà di Agraria, Università degli Studi di Palermo, viale delle Scienze, ed. 4 ingr. E, 90128 Palermo, Italy.

E-mail: vincenzo.bagarello@unipa.it

Key words: Arya and Paris model, laser diffraction method, particle size distribution, soil water retention curve.

Acknowledgements: this study was supported by grants from the Sicilian Region (Research projects ERODES and CISS). All authors set up the research, analyzed the results and wrote the paper.

Received for publication: 27 July 2012.

Accepted for publication: 20 October 2012.

CC Copyright C. Antinoro et al., 2012

Licensee PAGEPress, Italy

Journal of Agricultural Engineering 2012; XLIII:e18

doi:10.4081/jae.2012.e18

This article is distributed under the terms of the Creative Commons Attribution Noncommercial License (by-nc 3.0) which permits any noncommercial use, distribution, and reproduction in any medium, provided the original author(s) and source are credited. mization procedure (OPT). Comparison of $\alpha$-distributions and water retention shape indices obtained by the two methods (SH or LD) indicated that the shape-similarity hypothesis is better verified if the traditional sieve-hydrometer data are used to apply the AP model. The optimization procedure allowed more accurate predictions of the water retention curves than the traditional AP1 and AP2 procedures. Therefore, OPT can be considered a valid alternative to the more complex logistical model for estimating the water retention curve of Sicilian soils.

\section{Introduction}

The soil water retention curve, i.e. the relationship between soil water pressure head, $h$, and water content, $\theta$, expresses the capacity of soils to store water. This is a very important soil property for modelling water and chemical transport in unsaturated soils. Since laboratory procedures for the determination of $\theta(h)$ are time-consuming, great interest has been shown in models estimating the soil water retention curve from more easily measured and/or routinely surveyed soil data, such as texture, organic carbon content and bulk density.

Empirically derived pedotransfer functions (PTF) have often proved to be good predictors of soil water retention characteristics (Tietje and Tapkenhinrichs, 1993). However, their applicability may be limited to the variables used and the predictions obtained for other soils may be unreliable (Wösten et al., 2001). Consequently, users should first obtain a dataset of measured water retention curves and test several PTFs in order to decide whether or not a particular PTF is suitable for a particular region (Antinoro et al., 2008).

Another approach relies on the similarity between the shape of the particle-size distribution (PSD) and the water retention curve (Arya and Paris, 1981; Haverkamp and Parlange, 1986). In the model by Arya and Paris (AP) (1981), the pore size that is associated with a pore volume is determined by scaling the pore length of an ideal soil, calculated from the packing of spherical particles, to that of a natural soil using the scale factor $\alpha$. Originally, the AP model was seen to work relatively well for sandy soils with a constant $\alpha$ value $(\alpha=1.38)$ (Arya and Paris, 1981). Later investigations by Arya et al. (1982) showed that the average $\alpha$ varied among textural classes and ranged in value from 1.1 for fine-textured soils to 2.5 for coarse-textured ones. Tyler and Wheatcraft (1989) obtained single values of $\alpha$ for different textured materials and argued that it had a physical significance. Several other researchers (Schuh et al., 1988; Basile and D’Urso, 1997) considered $\alpha$ to be an appropriate parameter and suggested that a constant value for $\alpha$ is not suitable over the entire range of water retention curve. They also suggested that the predictions of water retention curves would improve using $\alpha$ values which vary over the range of particle sizes (Arya et al., 1999). Vaz et al. (2005) proposed an expression to calculate the $\alpha$ value for a set of 104 Brazilian soils as a function of the 
soil water content. Compared to the $\alpha$ as a function of soil water pressure originally proposed by Basile and D'Urso (1997), the relationship proposed by Vaz et al. appeared to be easier to apply in the model since it did not require an iterative procedure.

A limitation of the AP model is the difficulty in obtaining precise and detailed PSD data. For that reason, the AP model was generally calculated with few soil samples (Arya and Paris, 1981; Arya et al., 1999; Basile and D'Urso, 1997; Hwang and Powers, 2003). Validations of the AP model for estimating the soil water retention curve on a regional scale are limited because, in general, soil survey information only concerns the soil texture with a limited amount of PSD data, whereas the model requires at least twenty fractions to reasonably calculate the water retention curve (Arya et al., 1999). A possible solution to generate a detailed PSD from a limited amount of experimental PSD data is to fit a continuous model to the data. According to several researchers (Hwang et al., 2002; Hwang, 2004; Bagarello et al., 2009b), the PSD model by Fredlund et al. (2000) allows an accurate description of PSD experimental data for most soil texture classes to be made. Therefore, if the AP model is correct, the Fredlund model should show the best estimates for the soil's hydraulic properties (Hwang and Powers, 2003).

A detailed description of the soil PSD is also easily obtained by the laser diffraction (LD) technique (Loizeau et al., 1994; Buurman et al., 1997; Konert et al., 1997; Pieri et al., 2006). The LD method provides highly reproducible PSDs encompassing a broader range of sizes compared with conventional methods (Bah et al., 2009). The principal advantage of the LD method is that sample analysis can be performed almost 50 times faster than the traditional sieve-hydrometer (SH) method, thus making it possible to analyze a large number of samples in a short time (Arriaga et al., 2006). At the moment, the main problem with the LD method is the low correlation with the SH method. The PSDs determined by the two methods differ for a variety of reasons that are related to methodology, particle shape, mineralogy, refractive index and morphology (Zobeck, 2004). As an example, Bagarello et al. (2009a) found that for 635 Sicilian soils, the LD method systematically underestimated the clay content compared to the SH method. On the other hand, Segal et al. (2009) found satisfactory prediction of the water retention curve by the AP model when using PSD from SH and LD methods for 10 differently textured soils. However, to the best of our knowledge, testing the effects of the PSD measurement method on the prediction of the water retention characteristic has not been thoroughly investigated.

In this paper, we evaluated the performance of the AP model in estimating the soil water retention curves of 40 Sicilian soils from particle size distributions obtained by both the $\mathrm{SH}$ and $\mathrm{LD}$ methods. The effect of using a single value or a continuous expression of $\alpha$ along the PSD on the estimated soil water retention was tested. In addition, to improve the predictive ability of the AP model, an alternative procedure to define a soil-specific value of $\alpha$ was developed.

\section{Theory}

In the AP model, the PSD curve is divided into $n$ size fractions, and a solid mass in each fraction, $w_{i}\left(\mathrm{M} \mathrm{M}^{-1}\right)$ is assembled to form a hypothetical, cubic close-packed structure consisting of same-sized spherical particles. Arya and Paris (1981) found $n=20$ as a reasonable number of fractions, with fraction boundaries at particle diameters of $1,2,3,5$, $10,20,30,40,50,70,100,150,200,300,400,600,800,1000,1500$ and $2000 \mu \mathrm{m}$. The pore volume in each mass fraction is calculated from the bulk density and particle density measured on the natural soil structure. Starting with the first fraction, calculated pore volumes are progressively summed and considered filled with water. The volumetric water content, $\theta_{i}\left(\mathrm{~L}^{3} \mathrm{~L}^{-3}\right)$ at the upper bounds of successive mass fractions is obtained by dividing the cumulative pore volumes by the bulk volume of the sample. An equivalent pore radius, $r_{i}(\mathrm{~L})$, is calculated for each mass fraction and converted to soil water pressure head, $h_{i}(\mathrm{~L})$, using the capillarity equation. Calculated pressure heads are sequentially paired with calculated water contents to obtain the soil water retention curve.

To establish a relationship between $r_{i}$ and the particle radius, $R_{i}(\mathrm{~L})$, Arya and Paris (1981) scaled the pore length in an ideal soil to that of a corresponding natural soil. In an ideal soil, the pore length is equal to the sum of physical lengths of the particle diameters arranged in straight columns. Thus, for an ideal soil, the pore length is estimated by $2 n_{i} R_{i}$, where $n_{i}$ is the number of spherical particles for each fraction of the PSD. However, particles in a natural soil may contribute to pore length in more than one dimension. In addition, pressure head also depends on soil structure, organic matter, solutes and electrochemical properties of the solid surfaces (Arya et al., 1999). Therefore, the number of spherical particles, $N_{i}$, with diameter $R_{i}$, required to trace the pore length in the natural soil, corresponding with the ideal soil, is given by $N_{i}=n_{i}{ }^{\alpha}$. The resulting relationship between $r_{i}$ and $R_{i}$ is:

$$
r_{i}=0.816 R_{i} \sqrt{e n_{i}^{(1-\alpha)}}
$$

where $e$ is the void ratio given by

$$
e=\left(\rho_{s}-\rho_{b}\right) / \rho_{b}
$$

$\rho_{s}\left(\mathrm{M} \mathrm{L}^{-3}\right)$ is the particle density $\left(\approx 2.65 \mathrm{Mg} \mathrm{m}^{-3}\right)$ and $\rho_{b}\left(\mathrm{M} \mathrm{L}^{-3}\right)$ is the soil bulk density. The number of spherical particles, $n_{i}$, forming the cubic close-packed assemblage in the soil mass $w_{i}$ in the $i$ th fraction is given by

$$
n_{i}=\frac{3 w_{i}}{4 \pi R_{i}^{3} \rho_{s}}
$$

The soil water pressure head corresponding to the pore radius $r_{i}$ is then calculated by:

$$
h_{i}=-\frac{2 \sigma \cos \varpi}{\rho_{w} g r_{i}}
$$

where $\sigma$ is the surface tension of water $\left(\sigma=0.0728 \mathrm{~N} \mathrm{~m}^{-1}\right), \omega$ is the contact angle (assumed to be zero), $\rho_{w}\left(\mathrm{~kg} \mathrm{~m}^{-3}\right)$ is the density of water and $g\left(\mathrm{~m} \mathrm{~s}^{-2}\right)$ is the acceleration due to gravity.

For a given natural soil, the scale factor $\alpha$ can be obtained from the measured water retention, PSD, and packing density data by combining Eq. (1) to (4):

$$
\alpha_{i}=1-\frac{\ln \left[\frac{3}{2 e}\left(\frac{2 \sigma}{\rho_{w} g h_{i} R_{i}}\right)^{2}\right]}{\ln \left(\frac{3 w_{i}}{4 \pi R_{i}^{3} \rho_{s}}\right)}
$$

Therefore, for a given soil sample, $\alpha_{i}$ values can be calculated for each of the particle-sized fractions. According to Arya et al. (1999), meaningful estimations of $\alpha_{i}$ require that the number of particles in each particle-sized fraction should not be too small. Therefore, $\alpha_{i}$ values calculated for $n_{i}<10\left(\log n_{i}<1\right)$, generally occurring for the coarser particle fractions $(d \geq 0.8 \mathrm{~mm})$, were not used in this investigation. 


\section{Materials and methods}

\section{Soil sampling and laboratory measurements}

The Sicilian database considered includes 40 soil samples mainly collected from the districts of Trapani, Agrigento and Ragusa. All soil samples were collected in the A horizon.

A hanging water column apparatus (Burke et al., 1986) was used to measure water retention data on undisturbed soil cores (diameter 0.08 $\mathrm{m}$, height $0.05 \mathrm{~m}$ ) for $h$ values ranging from -0.05 to $-1.5 \mathrm{~m}$. At the end of the experiment, the soil bulk density was determined after oven drying and weighting of the undisturbed soil cores. The soil water content corresponding to $h$ values ranging from -3.37 to $-153.0 \mathrm{~m}$ was determined by a pressure plate apparatus (Dane and Hopmans, 2002) on soil samples (diameter $0.05 \mathrm{~m}$, height $0.01 \mathrm{~m}$ ) obtained by packing the sieved soil to the $\rho_{b}$ value of the undisturbed cores.

Depending on the sample, 6 to 13 points of the water retention curve were experimentally determined. The following form of the van Genuchten (1980) equation was used to fit experimental soil water retention data:

$$
h_{i}=-\frac{2 \sigma \cos \varpi}{\rho_{w} g r_{i}}
$$

where $\theta_{s}\left(\mathrm{~L}^{3} \mathrm{~L}^{-3}\right)$ is the saturated soil water content and $\alpha_{v G}$ and $n$ are fitting parameters. Implicit in Eq. (6) is the assumption that the residual water content can be set to zero. Bagarello and Iovino (2012) showed that Eq. (6) satisfactorily described the experimental $\theta(h)$ data of the Sicilian soils. An iterative non-linear regression procedure was employed to find the values of the fitting parameters that give the best fit between measured and modelled water retention data. This procedure was performed using the SOLVER procedure of Microsoft Excel software (Microsoft Company, Redmond, WA, USA). Three different initial parameter estimates were used for each soil to check the unicity of the solution.

The PSD was measured using the conventional SH method following $\mathrm{H}_{2} \mathrm{O}_{2}$ pretreatment to eliminate organic matter and clay deflocculation using sodium hexametaphosphate and mechanical agitation (Gee and Or, 2002). A total of 14 particle-sized classes were obtained for each sample.

The PSD was also determined by the LD method using the Laser Particle Sizer Analysette 22, Economy version (Fritsch GmbH, IdarOberstein, Germany) that allows 62 classes of grain size in the range of 0.1-600 $\mu \mathrm{m}$ to be determined. After wet sieving through a $710 \mu \mathrm{m}$ sieve, a subsample with a volume of $1.5 \mathrm{~mL}$ was introduced into the dispersion unit that contained $400 \mathrm{~mL}$ of deionized water. To maintain the random orientation of particles in suspension, the built-in automatic ultrasonic function was applied in the dispersion unit device. The ultrasonic action is an efficient dispersion method but can be critical for the particle size distribution because although the clay coatings are quickly removed, the quartz grains can be broken up. Following Chappel (1998), a 3-min ultrasonic action was used in the runs. To prevent the formation of gas bubbles during the movement of suspension into the dispersion unit device, the stirrer velocity was set to $60-70$ revolutions.

The suspension was then pumped through a sample cell placed in the convergent laser beam where the forward scattered light fell onto the 31 photosensitive sensor rings. Each run was set for $60 \mathrm{~s}$. To ensure that subsamples used allowed correct analysis, prior to each run, the detectors were aligned, the background was measured, and the sample dilution was controlled. All operations were controlled by a personal computer. Two additional texture fractions in the range $600-2000 \mu \mathrm{m}$ were determined by classical mechanical sieving. For both PSD measurement methods (i.e. SH or LD), soils were classified according to the US Department of Agriculture (USDA) classification (Gee and Or, 2002).

\section{Application of Arya and Paris models}

The 20 size fractions in a given PSD needed for the application of the AP model were those of Fredlund et al. (2000) fitted to the experimental PSD data obtained by the SH method

$$
P(d)=\frac{1}{\left[\ln \left(\exp (1)+\left(\frac{\alpha_{F}}{d}\right)^{n_{F}}\right)\right]^{m_{F}}}\left\{1-\left[\frac{\ln \left(1+\frac{d_{f}}{d}\right)}{\ln \left(1+\frac{d_{f}}{d_{m}}\right)}\right]\right\}
$$

where $P(d)$ is the fraction by mass of particles passing a particular diameter $d(\mathrm{~L}), \alpha_{F}(\mathrm{~L}), n_{F}$ and $m_{F}$ are fitting parameters, $d_{F}=0.001 \mathrm{~mm}$ and $d_{m}=0.0001 \mathrm{~mm}$ (Bagarello et al., 2009b).

Given that the LD method provided 64 particle sizes with a broader diameter range than the $\mathrm{SH}$ method, the $P(d)$ values corresponding to the 20 particle size limits of the AP model were determined by a log-linear interpolation procedure applied to the two neighbouring particle size limits (Bagarello et al., 2009b). This procedure was applied to obtain two strictly comparable PSDs from SH and LD methods.

The soil water content, $\theta_{A P, i}$, corresponding to the $i$-th fraction of the soil PSD was calculated as (Arya et al., 1999):

$$
\theta_{A P, i}=\theta_{s} \sum_{j=1}^{i} w_{i}, i=1,2,3, \ldots \ldots \ldots 20
$$

where $w_{i}$ is the soil mass for the mean particle diameter in each of the $i$-th fractions. The corresponding measured soil water content $\theta_{m, i}$, was obtained from Eq. (6) for each pressure head value, $h_{A P, i}$, calculated by the AP model.

In order to evaluate the existing formulation for the AP model, the scale factor $\alpha$ was determined according to two procedures. By the first procedure (AP1), the value of $\alpha$ equal to 1.38 originally proposed by Arya and Paris (1981) was considered for the available dataset. The second procedure (AP2) makes use of a logistical growth model that generates $\alpha$ as a continuous function of the PSD parameters (Arya $e t$ al., 1999). Parameters of the logistical model published by Arya et al. (1999) for five textural classes were used in the present study.

Despite being relatively more complicated to apply, the logistical model should yield improved predictions as compared to the use of a constant soil-specific $\alpha$ value (Basile and D'Urso, 1997; Arya et al., 1999; Vaz et al., 2005). However, a recent investigation by Segal et al. (2009) showed that the use of a constant soil-specific $\alpha$ value could also be an appropriate choice. Therefore, a single value of $\alpha$ was estimated for each soil of the dataset by an iterative non-linear regression technique that minimized the sum of squared residuals between $\theta_{m, i}$ and $\theta_{A P, i}$, the latter being calculated by the van Genuchten model (Eq. 6) for each $h_{i}$ value calculated by Eqs. (1) to (4) with a tentative value of $\alpha$. The optimization procedure was similar to that adopted by Arya and Paris (1981) and Nasta et al. (2009), but the water content values were considered instead of $\log h$ values.

\section{Data analysis}

The agreement between PSDs determined by the LD and conventional SH methods was assessed by calculating the coefficient of determination of linear regression $\left(r^{2}\right)$ and the mean bias error $(M B E)$, given by

$$
M B E=N^{-1} \sum_{i=1}^{N}\left(P_{\mathrm{LD}, i}-P_{\mathrm{SH}, i}\right)
$$

where $P_{\mathrm{LD}, i}$ and $P_{\mathrm{SH}, i}$ are the particle cumulative frequencies for a given diameter particle in each soil sample $(N=40)$, by the $\mathrm{LD}$ and SH meth- 
ods. Positive values of $M B E$ indicated that the LD method overestimated the cumulative particle frequency whereas negative values indicated underestimation. Statistical significance of $r$ was assessed by a onetailed t-test, and a two-tailed t-test was used to verify if $M B E$ values calculated for each of the 20 particle diameters were significantly different from zero. In all cases, $\mathrm{P}=0.05$ was taken as probability.

The performance of the AP model was evaluated by calculating the root mean square error (RMSE) as well as its systematic and unsystematic proportions (Willmott, 1982) as follows:

$$
\begin{aligned}
& R M S E=\left(N^{-1} \sum_{i=1}^{N}\left(\theta_{\mathrm{AP}, i}-\theta_{\mathrm{m}, i}\right)\right)^{0.5} \\
& R M S E_{s}=\left(N^{-1} \sum_{i=1}^{N}\left(\hat{\theta}_{\mathrm{AP}, i}-\theta_{\mathrm{m}, i}\right)\right)^{0.5} \\
& R M S E_{u}=\left(N^{-1} \sum_{i=1}^{N}\left(\theta_{\mathrm{AP}, i}-\hat{\theta}_{\mathrm{AP}, i}\right)\right)^{0.5}
\end{aligned}
$$

where $\theta_{\mathrm{AP}, i}$ is the water content value estimated by the AP model at a given pressure head, $\theta_{m, i}$ is the corresponding measured value, and $\hat{\theta}_{\mathrm{AP}, i}$ is the least-square regression value of $\theta_{m, i}$, given by $\hat{\theta}_{\mathrm{AP}, i}=a+\mathrm{b} \theta_{m, i}$. It has been argued that the commonly used correlation measures, $r$ or $r^{2}$, and tests of statistical significance in general, are often inappropriate or misleading when used to compare model predicted and observed variables (Willmott, 1982; Krause et al., 2005). One of the major drawbacks of $r^{2}$ is that only dispersion is quantified. A model which systematically over- or under-predicts the measured quantity will result in $r^{2}$ close to 1 even if all predictions were wrong. Therefore, RMSE should be preferred as an overall measure of model performance, as it gives an estimate of the average error in the units of the measured variable. Quantification of RMSE allows us to understand the proportion of $R M S E$ that arises from systematic errors that should be relatively easily dampened by a new parameterization of the model. In other words, it is a measure of the space available for local adjustment. The unsystematic proportion of $R M S E$ (i.e. $R M S E_{u}$ ) is representative of the noise level in the model being tested, and can be interpreted as a measure of its potential accuracy (Willmott, 1982). For a given overall level of accuracy (total RMSE), a good model is considered to have very low $R M S E_{s}$.

\section{Results and discussion}

\section{Soil datasets}

The soil dataset encompassed a wide range of texture classes. Soil classification obtained from SH data showed that sandy loam and loam soils were dominant, and only silt and sandy clay soils were not represented (Figure 1). A wide range of percentages was obtained for each texture fraction, although the datasets did not include soils with very high clay or silt content (Table 1). Wide ranges of bulk density and organic matter content were also found. Therefore, this dataset was representative of a wide range of physical soil conditions and as such was considered to be appropriate for a reliable assessment of the ability of the AP model to predict the water retention of Sicilian soils using different PSD measurement methods.

\section{Comparison between sieve-hydrometer and laser diffraction methods}

The LD method yielded PSDs that in most cases showed moderate to large deviations from those obtained by the traditional SH method. As an example, the PSDs of two medium textured soils determined by the
SH and LD methods are compared in Figure 2. For soil D25, the particle cumulative frequencies were relatively close to one another and, according to USDA classification, the soil was loam regardless of the laboratory method. For soil R1, the texture determined by the two methods showed discrepancies determining a different classification ( $\mathrm{SH}$ data: clay loam; LD data: sandy loam). The discrepancy in textural classification due to PSD measurement method was noted in $50 \%$ of cases (i.e. 20 of 40 soils of the dataset). In several cases, the more detailed description of the PSD obtained by the LD method highlighted a multimodal distribution that was not shown by the SH method (Figure 2). A comparison of cumulative frequency calculated by the two methods for each of the 20 particle diameters considered by the AP model is shown in Figure 3. Data were scattered around the 1:1 line and showed a moderate overall trend for the LD method to underestimate $P(d)$.

For each texture class, a significant correlation was found between the fractions predicted by the two methods, but the LD method under-

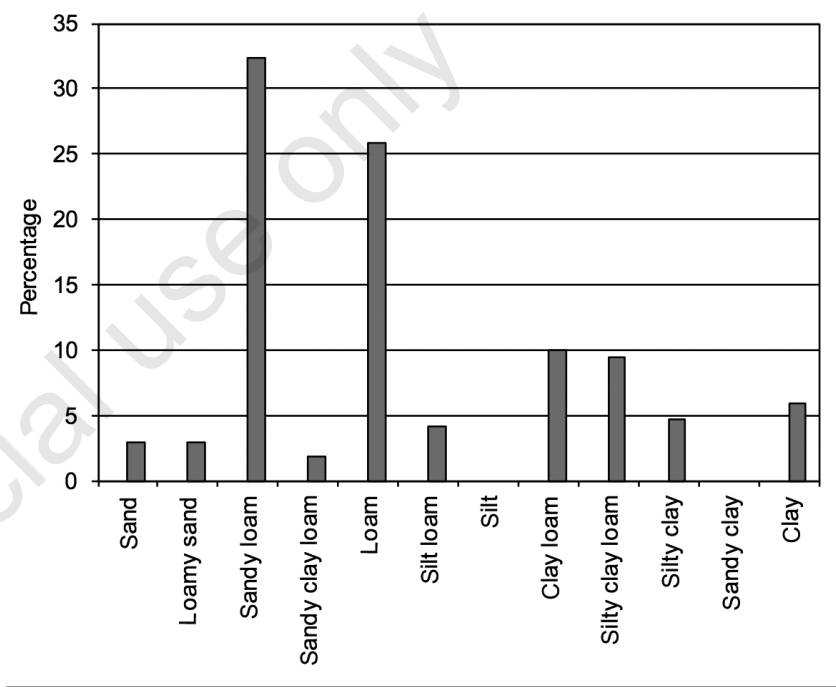

Figure 1. Texture composition of the dataset of Sicilian soils obtained from the sieve-hydrometer method.

\begin{tabular}{|c|c|c|c|c|c|}
\hline Variable & $\min$ & \multicolumn{4}{|c|}{ Dataset $(N=40)$} \\
\hline clSH (\%) & 6.7 & 56.7 & 23.3 & 21.3 & 12.5 \\
\hline siSH (\%) & 9.6 & 53.4 & 33.1 & 32.9 & 11.9 \\
\hline saSH (\%) & 10.2 & 83.6 & 43.6 & 42.1 & 20.8 \\
\hline$\rho b\left(\mathrm{Mg} \mathrm{m}^{-3}\right)$ & 0.895 & 1.700 & 1.300 & 1.308 & 0.163 \\
\hline $\mathrm{OM}(\%)$ & 0.20 & 4.50 & 1.65 & 1.52 & 0.94 \\
\hline$\theta s\left(m^{3} m^{-3}\right)$ & 0.308 & 0.620 & 0.461 & 0.454 & 0.066 \\
\hline$\alpha w \mathrm{G}(\mathrm{cm})$ & 0.011 & 0.492 & 0.096 & 0.045 & 0.117 \\
\hline$\alpha n$ & 2.108 & 2.465 & 2.234 & 2.190 & 0.103 \\
\hline$\alpha F(\mathrm{~mm})$ & 0.002 & 0.285 & 0.130 & 0.116 & 0.088 \\
\hline$n F$ & 0.529 & 19.879 & 2.876 & 1.957 & 3.504 \\
\hline$m F$ & 0.455 & 3.455 & 0.911 & 0.751 & 0.553 \\
\hline
\end{tabular}

Table 1. Statistics of soil properties and parameters of van Genuchten and Fredlund models for the dataset of Sicilian soils.

min, minimum value; $\max$, maximum value; $M e$, mean value; $M d$, median; $\sigma$, standard deviation; $N$, sample size; $c l \mathrm{SH}, s i \mathrm{SH}$ and $s a \mathrm{SH}$, clay, silt and sand content determined by the sieve-hydrometer method; $\rho b$, dry soil bulk density; OM, organic matter content; $\theta s$, saturated soil water content; $\alpha v G$ and $n$, parameters of van Genuchten water retention model (Eq. 6); $\alpha F, n F$, and $m F$, parameters of Fredlund model for particle-size distribution (Eq. 7) 
estimated the clay content and overestimated silt content with respect to the SH method (Table 2). Silt overestimation was only related to clay underestimation, because there was no significant difference in cumulative frequencies at the upper limit of the silt fraction $(d=50 \mu \mathrm{m})$ between the two measurement methods. For $s a$, the regression line with zero intercept fitted to the data obtained by the two methods (LD $v s \mathrm{SH}$ ) did not differ significantly from identity line (slope, $b=0.9812$ ). For $s i$ and $c l$ content, the regression lines had slopes greater $(b=1.335)$ and lower $(b=0.495)$ than 1 , respectively (Table 3$)$. Therefore, using the LD method, the clay content is expected to be underestimated by a factor of 2 , whereas the silt content is expected to be overestimated by 1.34 times.

For a database of 635 Sicilian soil samples, the LD method yielded $c l$ values that were 2.07 times lower than those obtained by the $\mathrm{SH}$ method (Bagarello et al., 2009b). Therefore, our results agree with those from previous studies. The two methods should be considered equivalent for discriminating between coarse $(d>50 \mu \mathrm{m})$ and fine fractions. However, they yielded different information on the relative amount of clay and silt particles within the fine fraction.

\section{Evaluation of existing procedures to estimate the soil water retention}

The existing procedures for applying the AP model yielded different results depending on whether $\mathrm{SH}$ or $\mathrm{LD}$ data were used to estimate the water retention curve. As expected, when the discrepancies between the PSDs determined by the two methods ( $\mathrm{LD}$ and $\mathrm{SH}$ ) were relatively small, the predicted water retention curves were similar. This was the case of the loam soil of Figure 2A, for which the water retention curves estimated from the SH and LD data were in closer agreement with one another and also with the measured water retention curve for both the AP1 and AP2 procedure (Figure 4A and B). However, a relatively good agreement between the water retention curves estimated from $\mathrm{SH}$ and LD was in some cases also obtained for soils that showed discrepancies in the PSDs, as soil R1 in Figure 2B (Figure 4C and D).

For a given PSD measurement method, procedure AP2 yielded more accurate predictions of the soil water retention curve than procedure

Table 2. Coefficient of determination, $\mathbf{r}^{2}$, and mean bias error of cumulative particle frequencies determined by the laser diffraction and sieve-hydrometer methods.

\begin{tabular}{lcc}
$d(\mathrm{Mm})$ & $\mathrm{r}^{2}$ & $\mathrm{M} B \mathrm{~B}$ \\
$c l$ & 0.724 & -0.116 \\
$s i$ & 0.711 & 0.127 \\
$s a$ & 0.883 & -0.011 \\
\hline For each texture class, $r^{2}$ and mean bias error $(M B E)$ in italics are significantly different from $0(\mathrm{P}=0.05)$.
\end{tabular}

Table 3. Intercept, $a$, slope, $b$, and coefficient of determination, $r^{2}$, of the linear regression between the optimized $\alpha$ values and soil bulk density, $\rho b\left(\mathrm{Mg} \mathrm{m}^{-3}\right)$, organic matter content, OM (\%), clay, $c l(\%)$, silt, si (\%) and sand, sa (\%) content.

\begin{tabular}{lcccccc} 
& \multicolumn{3}{c}{ SH method } & \multicolumn{4}{c}{ LD method } \\
& $a$ & $b$ & $r^{2}$ & $a$ & $b$ & $r^{2}$ \\
$\mathrm{\rho b}$ & 0.3722 & 0.6466 & 0.5365 & 0.3662 & 0.7213 & 0.4473 \\
$\mathrm{OM}$ & 1.3117 & -0.0601 & 0.1533 & 1.4148 & -0.0675 & 0.1295 \\
\hline $\mathrm{cl}$ & 1.4370 & -0.0096 & 0.6928 & 1.5669 & -0.0215 & 0.5277 \\
$\mathrm{si}$ & 1.3824 & -0.0051 & 0.1779 & 1.6226 & -0.0070 & 0.4657 \\
\hline $\mathrm{sa}$ & 0.9892 & 0.0051 & 0.5474 & 1.0554 & 0.0058 & 0.5290 \\
\hline
\end{tabular}

SH, sieve-hydrometer; LD, laser diffraction.
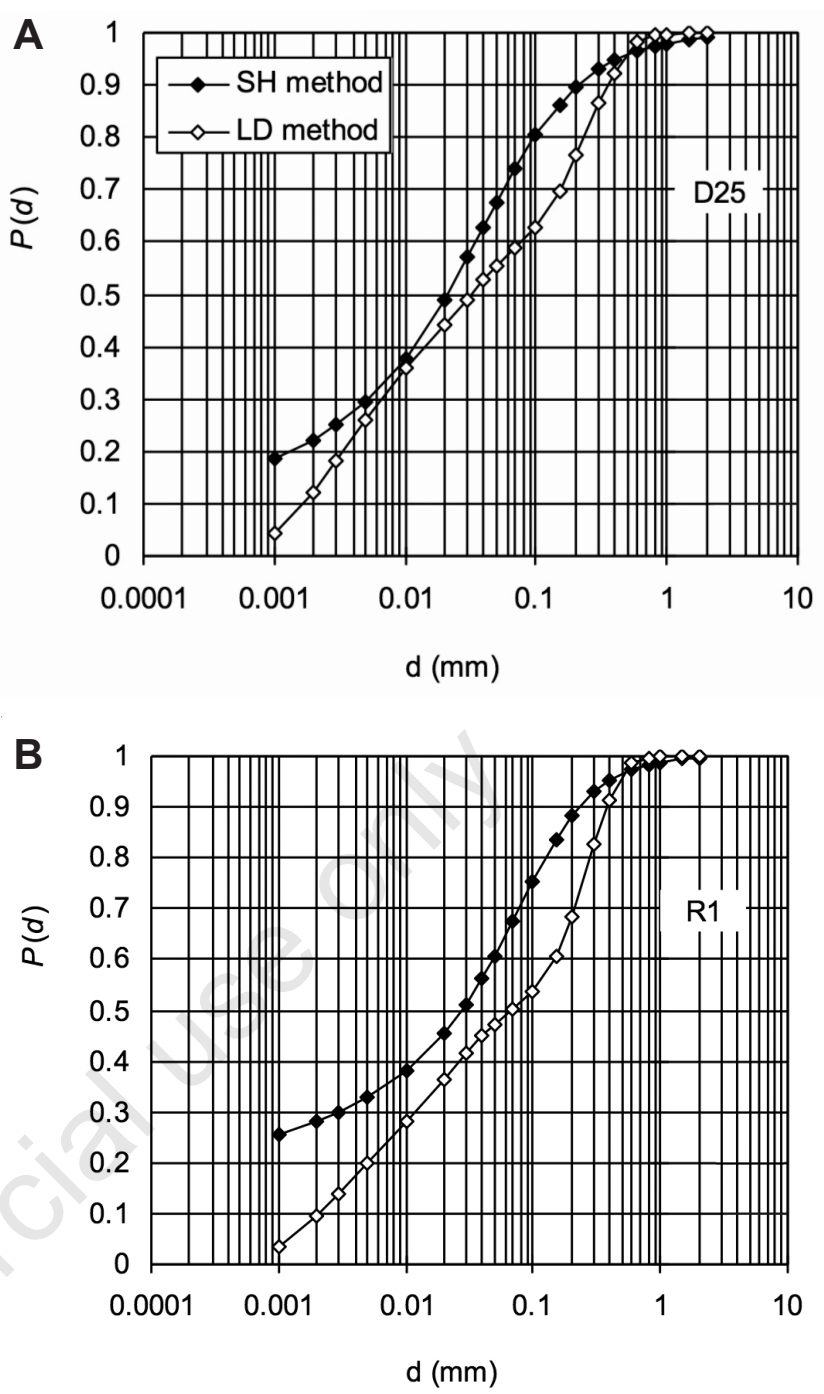

Figure 2. Particle-size distribution determined by the sievehydrometer (SH) and laser diffraction (LD) methods for two medium textured soils of the calibration dataset.

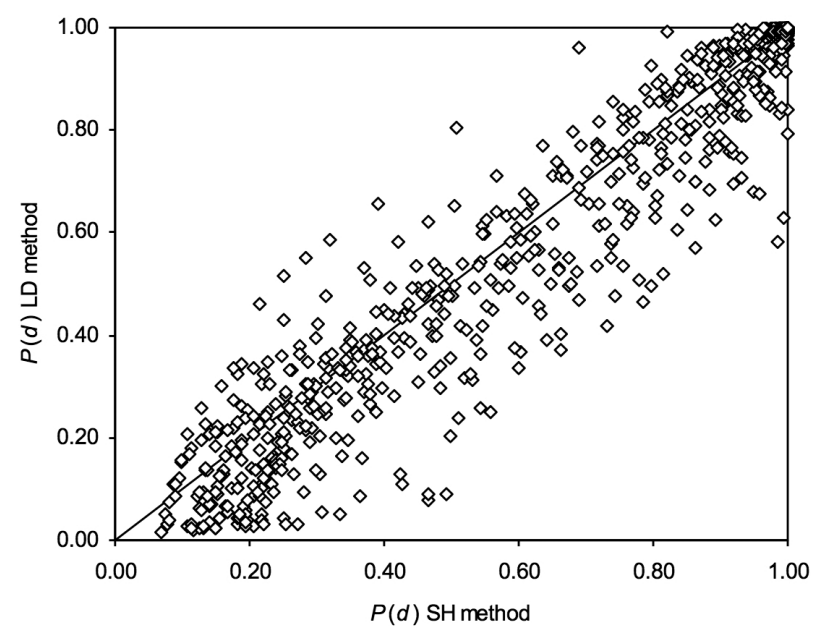

Figure 3. Comparison between particle-size cumulative frequency obtained for a given diameter by the sieve-hydrometer $(\mathrm{SH})$ and laser diffraction (LD) methods. 
AP1, since the comparison between $\theta_{\mathrm{AP}, i}$ and $\theta_{\mathrm{m}, i}$ showed lower $R M S E$ values (Table 4). Procedure AP1 tended to overpredict the water content in the wet range and to underpredict it in the dry range (Figure 5). Underestimation of water retention data in the dry range of soil moisture was somewhat expected (Tyler and Wheatcraft, 1989) given that, as soil dries, a significant percentage of water is held as films or in dead-end soil pores. Therefore, $\theta_{\mathrm{m}, i}$ was higher than $\theta_{\mathrm{AP}, i}$ because the AP model assumes complete desorption of all pores of a given size class when the corresponding capillary pressure is applied. On the other hand, at high pressure head values, the presence in natural soils of structural cracks or macropores that drain at very low suction might have yielded measured $\theta$ values lower than those estimated by the AP model under the hypothesis of homogeneous pore domain.

A similar biased estimation of $\theta$ was found by Arya et al. (1999). They proposed using a variable $\alpha$ with PSD to overcome this. Indeed, application of the logistical model with parameters gathered from literature to Sicilian soils reduced the observed bias as can be detected by the lower values of $R M S E_{s}$ for AP2 in comparison to AP1 and also increased the accuracy of the predictions (lower $R M S E_{u}$ ) (Table 4, Figure 5). Therefore, the use of a variable $\alpha$ value estimated by the logistical model (procedure AP2) is preferable to that of a unique $\alpha=1.38$ value (procedure AP1) to predict the water retention charac-
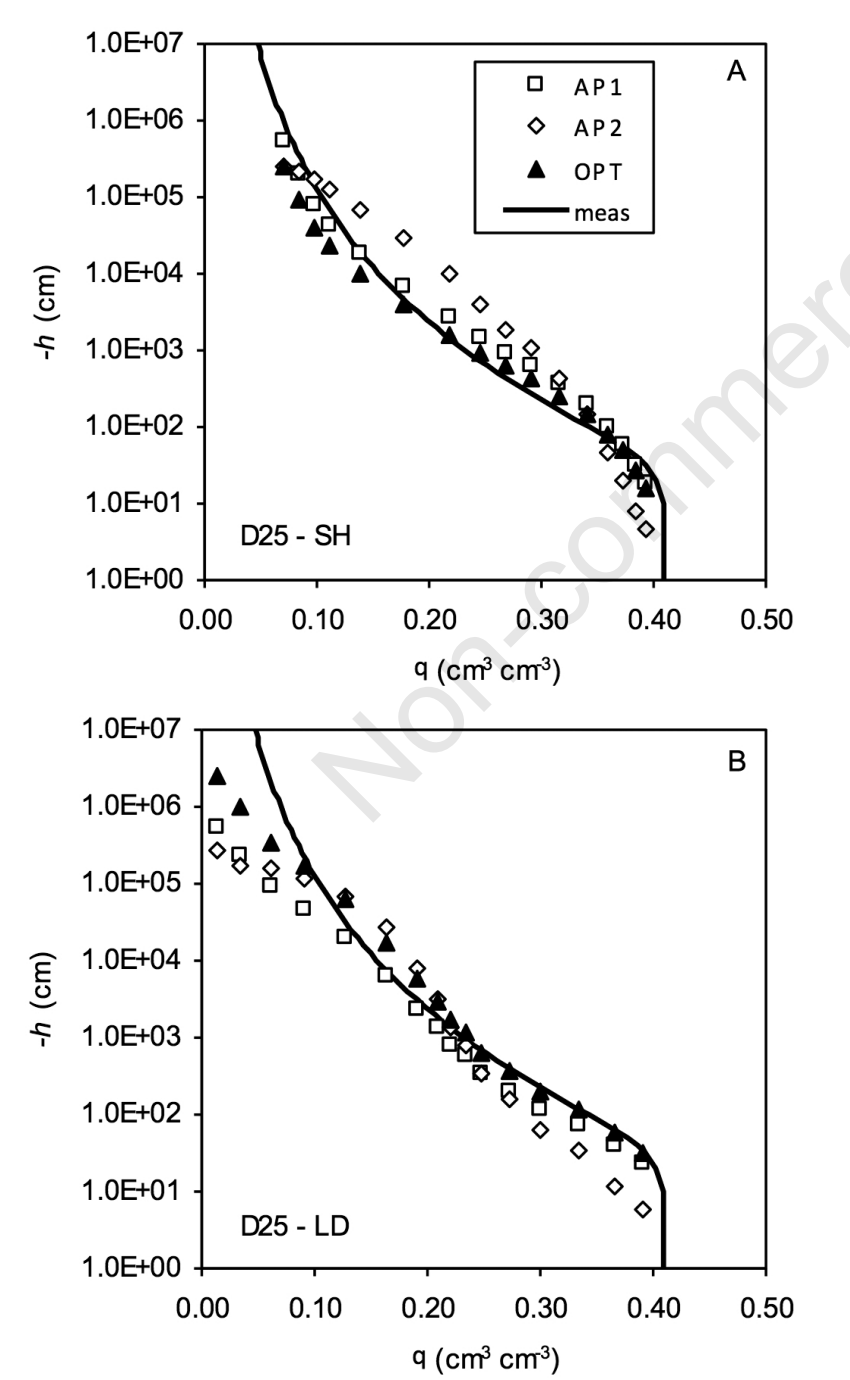

teristics of the Sicilian soils by the Arya and Paris model.

For procedure AP1, the $\theta_{\mathrm{AP}, i}$ values estimated from $\mathrm{SH}$ data were more accurate than those estimated from LD data (Table 4). The opposite result was obtained for procedure AP2. In any case, however, the $R M S E$ values obtained with the two PSD measurement techniques

Table 4. Total, systematic and unsystematic root mean square errors (Eqs. 10, 10a, 10b) of $\theta_{A P}$ values estimated by different procedures for the soils of the dataset.

\begin{tabular}{lcccc}
$\begin{array}{l}\text { AP model } \\
\text { application } \\
\text { procedure }\end{array}$ & $\begin{array}{c}\text { PSD } \\
\text { measurement } \\
\text { method }\end{array}$ & RMSE & RMSES & RMSEEu \\
AP1 & SH & 0.0645 & 0.0445 & 0.0467 \\
& LD & 0.0689 & 0.0228 & 0.0626 \\
AP2 & SH & 0.0599 & 0.0393 & 0.0452 \\
& LD & 0.0596 & 0.0165 & 0.0573 \\
\hline OPT & SH & 0.0299 & 0.0085 & 0.0286 \\
& LD & 0.0506 & 0.0156 & 0.0481 \\
\hline
\end{tabular}

AP, Arya and Paris model; PSD, particle-size distribution; RMSE, RMSEs, RMSEu, root mean square error; SH, sieve-hydrometer; LD, laser diffraction; OPT, optimization procedure.
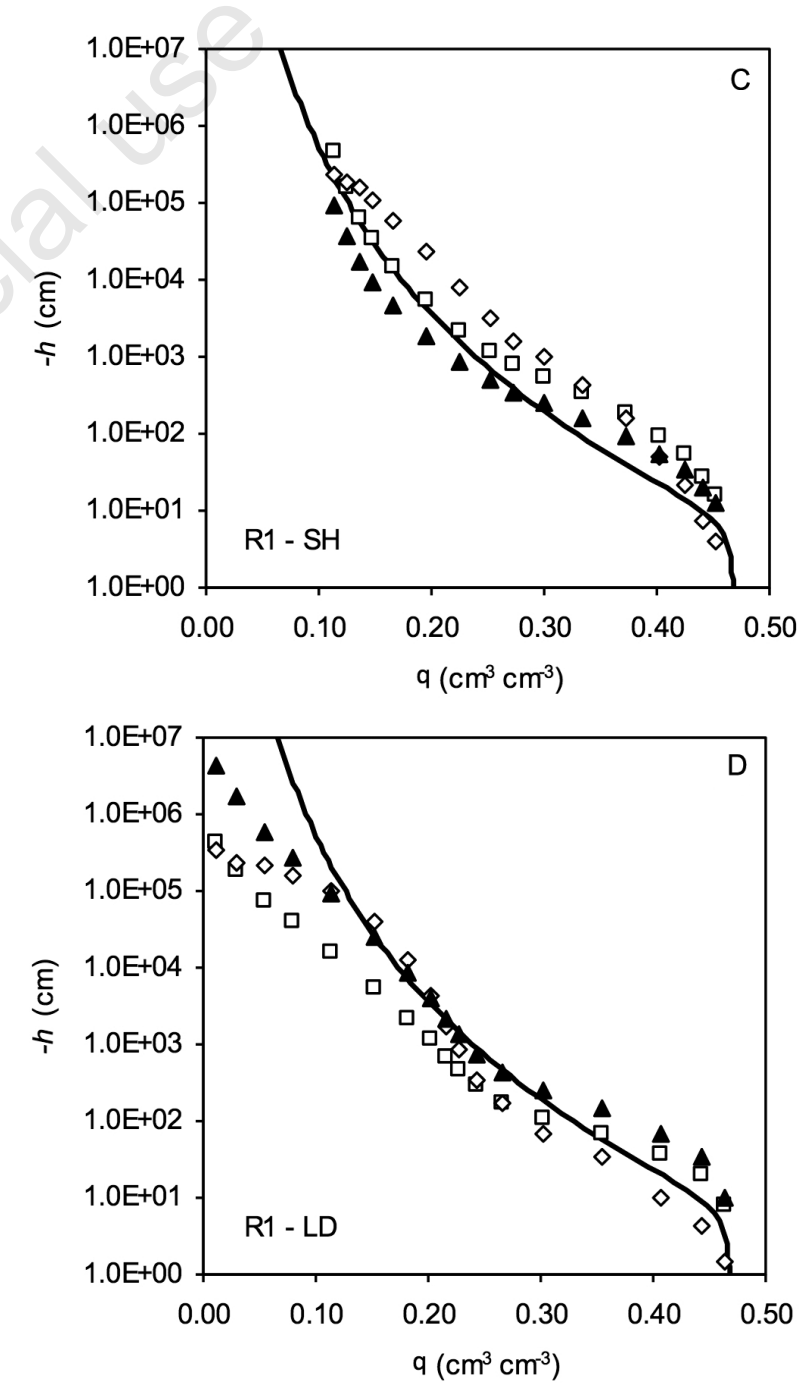

Figure 4. Water retention curves estimated by different procedures of the Arya and Paris (AP) model from particle-size distribution data determined by the sieve-hydrometer (SH) and laser diffraction (LD) methods for two soils of the dataset. OPT, optimization procedure. 
were very similar. Regardless of the applied procedure, the discrepancies in the predictions obtained by the two PSD measurement methods were particularly noticeable in the dry range (Figure 5), probably as a consequence of the systematic differences observed in the two PSDs for $d \leq 5 \mu \mathrm{m}$ (Table 2). In particular, underestimation of $\theta$ calculated by the LD data for the lower water content values (Figure 5) might be a consequence of underestimation of the clay fraction in the LD technique. In fact, higher clay content is expected to result in a higher measured $\theta$ in the dry range that the AP model could not predict if applied to LD data. For a given pressure head, $\theta$ values estimated from LD data were generally lower than those estimated from SH method and water retention curves extended to much lower water contents (Figure 4). Similar total RMSE values indicate that application of the AP model to SH or LD data allowed us to predict the water retention curves of Sicilian soils with the same level of accuracy (Table 4). However, the $\mathrm{SH}$ data resulted in $R M S E_{s}$ values that were almost two times those obtained from LD data, thus indicating a systematic deviation of the predicted $\theta_{A P}$ (Figure 5). On the other hand, the $R M S E_{u}$ values for the SH method were always lower than those from the LD method (Table 4). Therefore, the SH data can be considered inherently more appropriate than LD data to determine $\theta_{A P}$. The evidence of a sys- tematic error in $\theta_{A P}$ values estimated from SH data also suggest that a specific calibration could be conducted to improve the accuracy in the predicted water retention of Sicilian soils.

The $\alpha_{i}$ calculated using Eq. (5) for each soil and diameter fraction were more variable for the LD method than for the SH method and skewed towards high values (Figure 6). The average value of $\alpha_{i}$ was 1.119 for the SH method and 1.253 for the LD method, with standard deviation of 0.269 and 0.396 , respectively. For the ideal soil assumed by Arya et al. (1999), $\alpha$ should be equal to 1 . Considering that $\alpha$ is the scaling parameter between the PSD and the water retention curve of the natural soil, the frequency distributions in Figure 6 indicate that the PSD determined by the SH method is on average more representative of the ideal soil than those determined by LD method.

The following water retention shape index, $p_{m}$, proposed by Haverkamp et al. (2005) can be used to characterize the retention behavior of a particular soil with a single number:

$$
p_{m}=\frac{1}{\theta_{s}-\theta_{r}} \int_{\theta_{r}}^{\theta_{s}} \frac{d(\ln \theta)}{d(\ln h)} d \theta
$$
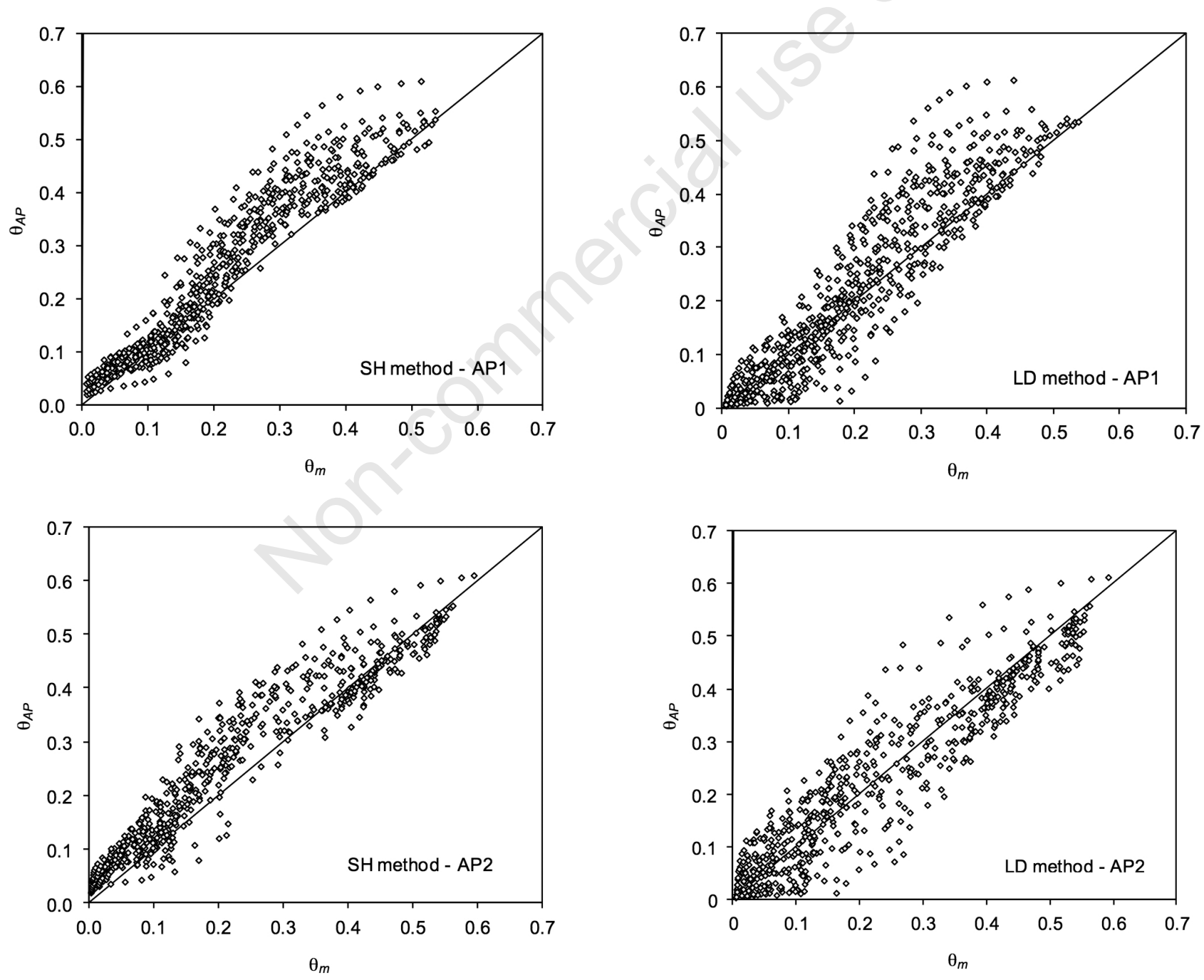

Figure 5. Water content values, $\theta_{\mathrm{AP}}$, predicted by procedures Arya and Paris (AP1 and AP2) from sieve-hydrometer (SH) and laser diffraction $(\mathrm{LD})$ data versus measured water content values, $\theta_{\mathrm{m}}$. 
For a given procedure (AP1 or AP2), the water retention shape index of each soil was calculated from the measured $\theta_{m}(h)$ data and compared with the two $p_{m}$ values obtained by the corresponding $\theta_{A P}(h)$ estimated from SH and LD data. A comparison of $p_{m}$ values for measured and AP2-predicted water retention calculated from SH- and LD-measured PSD is shown in Figure 7. With only a few exceptions, the water retention shape indices of $\theta_{A P}(h)$ estimated from SH data and those for the $\theta_{m}(h)$ data show very close agreement, being distributed evenly around the 1:1 line. On the other hand, the $p_{m}$ values of $\theta_{A P}(h)$ from LD data were systematically overestimated. For the $\mathrm{SH}$ method, the ratio of the estimated to measured $p_{m}$ values ranged from 0.61 to 13.5 with a mean ratio of 1.60. For $\mathrm{LD}$ data, the mean ratio between estimated and measured $p_{m}$ values was 3.67 and an overestimation of the water retention shape index up to a factor of 30.43 was observed. Both analyses of the distributions of $\alpha$ values and comparison of water retention shape indices showed that the shape-similarity hypothesis between PSD and water retention curve is probably more valid when $\mathrm{SH}$ data are used for AP model application.

Another reason for the relatively poor predictive ability of the PSD determined by the LD method may be due to the influence of the observed multimodal distribution of pore size that is not taken into account by the unimodal van Genuchten equation for soil water retention. Unfortunately, the number of $\theta(h)$ data was too small to fit a more general water retention model as widely demonstrated in the literature (Ross and Smettem, 1993; Durner, 1994; Zurmuhl and Durner, 1998; Coppola, 2000; Dexter et al., 2008; Kutílek et al., 2009).

\section{Conclusions}

The AP model was applied to PSDs of 40 Sicilian soils obtained by both the conventional SH and the innovative LD methods. According to existing procedures suggested by Arya and Paris (1981) and Arya et al. (1999), the scale factor $\alpha$ was set equal to 1.38 or estimated by a logistical model with parameters gathered from literature. For both SH and LD data, the use of $\alpha$ derived by a continuous function of soil PSD allowed a more accurate prediction of the water retention than the original procedure involving the use of $\alpha=1.38$. Therefore, despite being attractive for its simplicity, the use of a unique $\alpha$-value for a dataset consisting of soils with variable texture is not recommended.

Despite the differences in PSDs obtained by the SH and LD methods, we found the same level of accuracy in predicting water retention by a given procedure (AP1 or AP2) from SH and from LD data. The water retention curves estimated from $\mathrm{LD}$ data extended to a much drier range and, for a given pressure head, the water content values were generally lower than those for the SH method. These discrepancies were attributed to underestimation of PSD for the finest diameter particles by the LD method. Analysis of systematic and unsystematic RMSE showed that the soil water retention estimated from the SH method was inherently more accurate than that estimated from the LD method, but it was affected by an estimation bias that could be corrected by a specific calibration. The SH method yielded scale factors $\alpha_{i}$ that were less variable than those from the LD method and water retention shape indices in closer agreement with the measured data. Therefore, the shape-similarity hypothesis of the AP model is better verified if the traditional sieve-hydrometer data are used. However, multi-modality of particle-size distribution that was not accounted for in measured water retention data, may be another factor that affected the predictive ability of the PSD determined by the LD method.

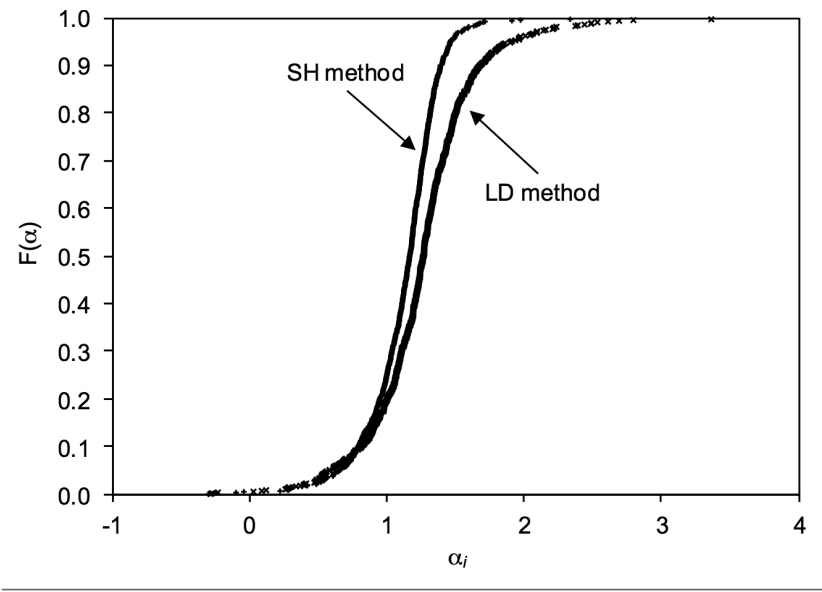

Figure 6. Frequency distributions of $\alpha_{i}$ values calculated from particle-size distribution determined by the sieve-hydrometer (SH) and laser diffraction (LD) methods.
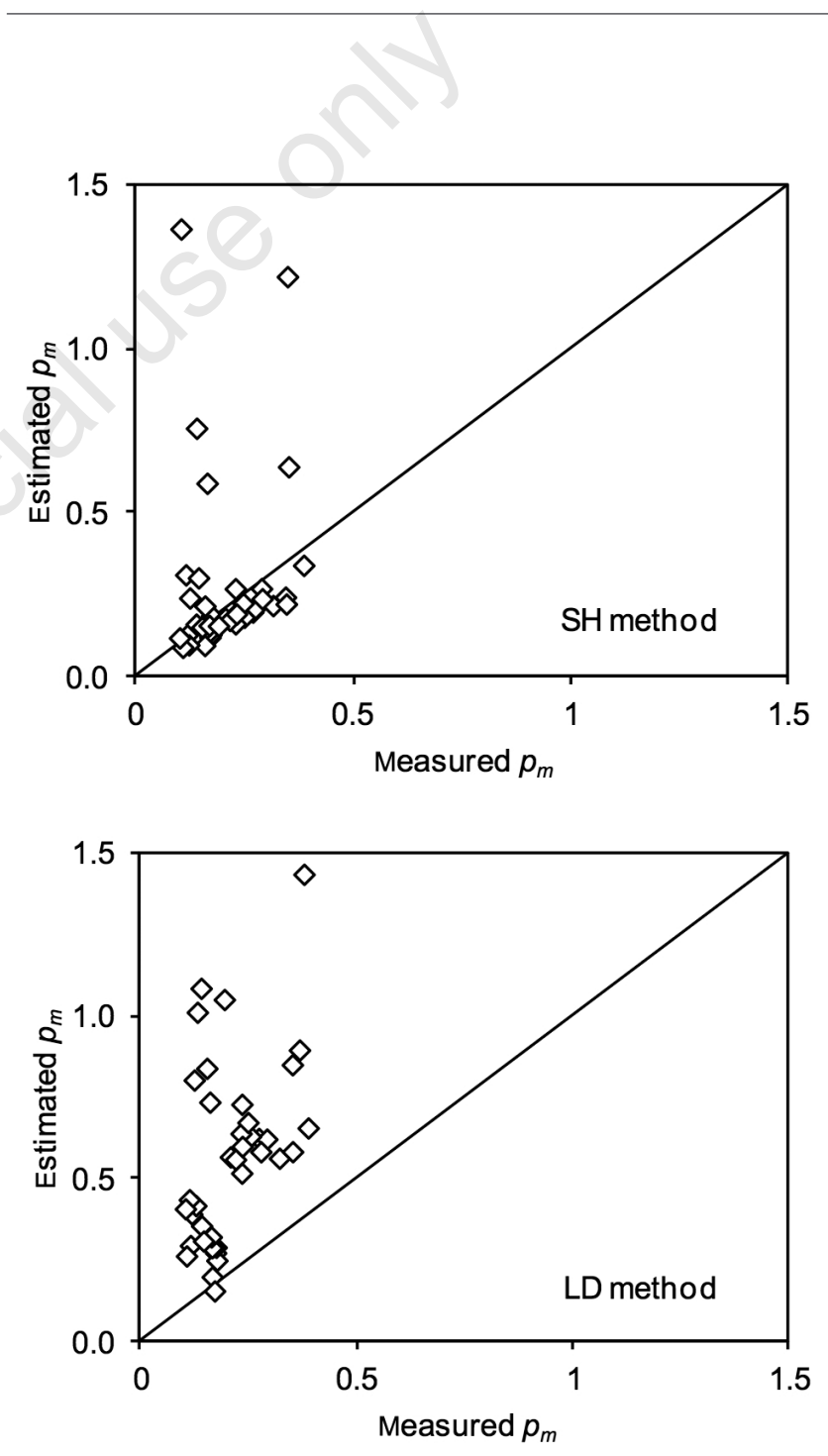

Figure 7. Comparison between the water retention shape index, $p_{m}$, obtained by the measured water retention and the shape index of the water retention estimated by the Arya and Paris model applied to different particle-size distribution data. SH, sievehydrometer; LD, laser diffraction. 


\section{References}

Antinoro C., Bagarello V., Castellini M., Giangrosso A., Giordano G., Iovino M., Sgroi A., 2008. Predicting the water retention characteristic of Sicilian soils by pedotransfer functions. In: Santini A., et al., eds. Irrigation in Mediterranean agriculture: challenges and innovation for the next decades. Options Méditerranéennes, series A, no. 84, Ideaprint, Bari, pp 245-256.

Arriaga F.J., Lowery B., Mays M.D. 2006. A fast method for determining soil particle size distribution using a laser instrument. Soil Sci. 171:663-674.

Arya L.M., Leij F.J., van Genuchten M.T., Shouse P.J. 1999. Scaling parameter to predict the soil water characteristic from particle-size distribution data. Soil Sci. Soc. Am. J. 63:510-9.

Arya L.M., Paris J.F. 1981. A physicoempirical model to predict the soil moisture characteristic from particle-size distribution and bulk density data. Soil Sci. Soc. Am. J. 45:1023-30.

Arya L.M., Richter J.C., Davidson S.A. 1982. A comparison of soil moisture characteristic predicted by the Arya-Paris model with laboratory-measured data. AgRISTARS Tech. Rep. SM-L1-04247, JSC-17820. NASA-Johnson Space Center, Huston, TX, USA.

Bagarello V., Di Stefano C., Ferro V., Iovino M., Mirabile S., 2009a. Determinazione della distribuzione granulometrica del suolo mediante diffrattometria laser. IX Convegno Nazionale dell'Associazione Italiana di Ingegneria Agraria, Ischia porto (NA), memoria no. 3-5. [In Italian].

Bagarello V., Iovino M. 2012. Testing the BEST procedure to estimate the soil water retention curve. Geoderma 187-188:67-76.

Bagarello V., Provenzano G., Sgroi A. 2009b. Fitting particle size distribution models to data from Burundian soils for the BEST procedure and other purposes. Biosyst. Eng. 104:435-41.

Bah A.R., Kravchuk 0., Kirchhof G. 2009. Fitting performance of particle-size distribution models on data derived by conventional and laser diffraction techniques. Soil Sci. Soc. Am. J. 73:1101-7.

Basile A., D‘Urso G., 1997. Experimental corrections of simplified methods for predicting water retention curves in clay-loamy soils from particle-size determination. Soil Technol. 10:261-72.

Burke W., Gabriels D., Bouma J. 1986. Soil structure assessment. Balkema, Rotterdam, The Netherlands.

Buurman P., Pape Th., Muggler C.C. 1997. Laser grain-size determination in soil genetic studies. 1. Practical problems. Soil Sci. 162:2118.

Chappel A. 1998. Dispersing sandy soil for the measurement of particle size distributions using optical laser diffraction. Catena 31:271318.

Coppola A. 2000. Unimodal and bimodal descriptions of hydraulic properties for aggregated soils. Soil Sci. Soc. Am. J. 64:1252-62.

Dane J.H., Hopmans J.W. 2002. Water retention and storage: laboratory. In: Dane J.H., Topp G.C., eds. Methods of soil analysis, physical methods, Part 4, 3rd edition. Madison, WI, USA, pp 688-692.

Dexter A.R., Czyz E.A., Richards G., Reszkowska A. 2008. A user-friendly water retention function that takes account of the textural and structural pore spaces in soil Geoderma 143:243-53.

Durner W. 1994. Hydraulic conductivity estimation for soils with heterogeneous pore structure. Water Resour. Res. 30:211-23.

Fredlund M.D., Fredlund D.G., Wilson G.W. 2000. An equation to represent grain-size distribution. Can. Geotechn. J. 37:817-27.

Gee G.W., Or D. 2002 . 2.4 Particle-size analysis. In: Dane J.H., Topp G.C., co-eds. Methods of soil analysis. Part 4, Physical methods. SSSA Book Series 5, Madison, WI, USA, pp 255-93.
Haverkamp R., Leij F.J., Fuentes C., Sciortino A., Ross P.J. 2005. Soil water retention: I. Introduction of a shape index. Soil Sci. Am. J. 69:1881-90.

Haverkamp R., Parlange J.-Y. 1986. Predicting the water-retention curve from particle-size distribution. Soil Sci. Soc. Am. J. 142:32539.

Hwang S.I. 2004. Effect of texture on the performance of soil particlesize distribution models. Geoderma 123:363-71.

Hwang S.I., Lee K.P., Lee D.S., Powers S.E. 2002. Models for estimating soil particle-size distributions. Soil Sci. Soc. Am. J. 66:1143-50.

Hwang S.I., Powers S.E. 2003. Using particle-size distribution models to estimate soil hydraulic properties. Soil Sci. Soc. Am. J. 67:1103-12.

Konert M., Vandenberghe J. 1997. Comparison of laser grain size analysis with pipette and sieve analysis: a solution for the underestimation of the clay fraction. Sedimentology 44:523-5.

Krause P., Boyle D.P., Bäse F. 2005. Comparison of different efficiency criteria for hydrologica model assessment. Adv. Geosci. 5:89-97.

Kutílek M., Jendele L., Krejca M. 2009. Comparison of empirical, semiempirical and physically based models of soil hydraulic functions derived for bimodal soils. J. Contam. Hydrol. 104:84-9.

Loizeau J.L., Arbouille D., Santiago S., Vernet J.P. 1994. Evaluation of a wide range laser diffraction grain size analyzer for use with sediments. Sedimentology 41:353-61.

Nasta P., Kamai T., Chirico G.B., Hopmans J.W., Romano N. 2009. Scaling soil water retention functions using particle-size distribution. J. Hydrol. 374:223-34.

Pieri L., Bittelli M., Rossi Pisa P. 2006. Laser diffraction, transmission electron microscopy and image analysis to evaluate a bimodal Gaussian model for particle size distribution in soil. Geoderma 135:118-32.

Ross P.J., R.J. Smettem. 1993. Describing soil hydraulic properties with sums of simple functions. Soil Sci. Soc. Am. J. 57:26-9.

Schuh W.M., Cline R.L., Sweeney M.D. 1988. Comparison of a laboratory procedure and a textural model for predicting in situ soil water retention. Soil Sci. Soc. Am. J. 52:1218-27.

Segal E., Shouse P.J., Bradford S.A., Skaggs T.H., Corwin D.L. 2009. Measuring particle size distribution using laser diffraction: implications for predicting soil hydraulic properties. Soil Sci. 174:63945.

Tietje 0., Tapkenhinrichs M. 1993. Evaluation of pedo-transfer functions. Soil Sci. Soc. Am. J. 57:1088-095.

Tyler S.W., Wheatcraft S.W. 1989. Application of fractal mathematics to soil water retention estimation. Soil Sci. Soc. Am. J. 53:987-96.

van Genuchten M.Th. 1980. A closed form equation for predicting the hydraulic conductivity of unsaturated soils. Soil Sci. Soc. Am. J. 44:892-8.

Vaz C.M.P., de Freitas Iossi M., de Mendonça Naime J., Macedo Á., Reichert J.M., Reinert D.J., Cooper M. 2005. Validation of the Arya and Paris water retention model for Brazilian soils. Soil Sci. Soc. Am. J. 69:577-83.

Willmott C.J. 1982. Some comments on the evaluation of model performance. Bull. Am. Meteorol. Soc. 63:1309-13.

Wösten J.H.M., Pachepsky Y.A., Rawls W.J. 2001. Pedotransfer functions: bridging the gap between available basic soil data and missing soil hydraulic characteristics. J. Hydrol. 251:123-50.

Zobeck T.M. 2004. Rapid soil particle size analyses using laser diffraction. Appl. Eng. Agric. 20:633-9.

Zurmuhl T., W. Durner. 1998. Determination of parameters for bimodal hydraulic functions by inverse modeling. Soil Sci. Soc. Am. J. 62:874-80. 